\title{
FORMAÇÃO POR COMPETÊNCIA: EXPERIÊNCIA NA ESTRUTURAÇÃO DO PROJETO PEDAGÓGICO DE UM CURSO DE ADMINISTRAÇÃO
}

\author{
COMPETENCY-BASED EDUCATION: \\ EXPERIENCE OF ORGANIZING \\ A BUSINESS ADMINISTRATION TEACHING PROJECT
}

\author{
Recebido em: 07/03/2014 A Aprovado em: 19/05/2014 \\ Avaliado pelo sistema double blind review \\ Editora Científica: Manolita Correia Lima
}

\author{
HONG YUH CHING hongching@fei.edu.br \\ EDSON COUTINHO DA SILVA \\ PAULO HENRIQUE TRENTIN \\ CENTRO UNIVERSITÁRIO DA FEI
}

\begin{abstract}
RESUMO
O artigo tem como objetivo relatar a experiência na estruturação do projeto pedagógico por competência em um curso de Administração. Para o desenvolvimento das habilidades e competências, foram consideradas as constantes nas Diretrizes Curriculares Nacionais (DCN) da Resolução 04/2005, na Pesquisa Nacional do Conselho Federal de Administração e Conselho Regional da Administração (CFA/CRA) de 20 Ir e nos materiais de uma consultoria. Para atender aos objetivos, a pesquisa foi definida, com relação aos fins, como sendo descritiva, e com relação aos meios, como sendo uma pesquisa ação. A estratégia de abordagem é o estudo de caso. Este artigo propõe um roteiro para implantação de um Projeto Pedagógico de Curso (PPC) baseado em formação por competências ou pedagogia das competências e aprendizagem significativa, a partir de uma situação empírica. Constatou-se que qualquer futura implantação de uma nova proposta pedagógica por competência necessitará de uma mudança de mentalidade e paradigma do coordenador do curso, do seu corpo docente, dos alunos e, ainda, da IES para a consecução da formação dos alunos. Esta experiência visa contribuir para o estado da arte de administrar e educar, tendo em vista uma educação sólida, eficaz para atender aos interesses das organizações que contratarão esses profissionais.
\end{abstract}

Palavras-chave: competências; projeto pedagógico; pedagogia das competências; formação por competência.

\begin{abstract}
The objective of this paper is to report the experience of organizing a teaching project, by competence, for a course in business administration. The skills and competences included in the CTP (Course Teaching Project) were those listed in CNE [National Education Curriculum] Resolution 04/2005, the CFA/CRA [Federal Business Administration Board/ Regional Business Administration Board] 2011 National Survey and the material from a consultancy company. The research was defined as being descriptive and action-research. This paper proposes a roadmap for the deployment of a competence-based CTP or one based on competence teaching and significant learning within an empirical situation. Any implementation of a new competence-based teaching proposal would require a change in the mentality and paradigm in the course coordinator, teachers and students, as well as a reorganization of higher education institutions committed to their students' education. This experience aims to contribute to the state of the art in administration education for a solid and effective preparation that meets the interests of the organizations that will hire these professionals.
\end{abstract}

Keywords: competencies; teaching project; competence teaching; competence-based education. 


\section{INTRODUÇÃO}

Nas edições de julho e fevereiro de 2013 da Revista do Administrador Profissional, do Conselho Regional da Administração (CRA/sP), os presidentes da GR Properties e Votorantim Industrial, respectivamente, relataram que há um descompasso entre as demandas do mercado e a formação do administrador pelas instituições de ensino superior. Para eles, os cursos de administração estão antiquados e tem deixado a desejar, ensinam coisas técnicas e não ensinam a lidar com pessoas e resolver problemas além dos estudantes não possuírem visão global de negócios.

$\mathrm{O}$ assunto qualidade no ensino de Administração foi matéria de capa da edição de nov/dez 2013 da Revista Brasileira de Administração (RBA), do Conselho Federal de Administração (CFA). Segundo dados do Censo da Educação Superior 2012, existem 2160 cursos de bacharelado em Administração e 850.000 estudantes, constituindo-se no maior curso de graduação no Brasil. Somos os maiores, porém e a qualidade, como anda? Essa matéria mostra que houve uma evolução discreta na nota media do Enade de Administração, indo de 2,29 em 2009 para 2,33 em 2012. A tão almejada qualidade dos cursos só se tornará efetiva à medida que se promovam mudanças de atitudes e comportamentos (OLIVEIRA, 2005).

O Parecer 776/97 do CNE Conselho Nacional de Educação, que orienta para as diretrizes curriculares dos cursos de graduação, preconiza que os cursos de graduação precisam ser conduzidos, por meio das Diretrizes Curriculares, a abandonar as características de que muitas vezes se revestem, quais sejam as de atuarem como instrumentos de transmissão de conhecimento e informações. Passando a orientar-se para oferecer uma formação básica, preparando o graduando para enfrentar os desafios das rápidas transformações da sociedade, do mercado de trabalho e das condições de exercício profissional.

O ensino superior de Administração ganhou maior conotação após a Resolução 04/2005, que estabeleceu as Diretrizes Curriculares Nacionais (DCN). Essas diretrizes, em consonância com a Lei de Diretrizes Básicas (LDB), procuram garantir uma organização curricular do curso baseada 
no projeto pedagógico, com conteúdos que revelem inter-relações com a realidade nacional e internacional por meio de tecnologias inovadoras e, ainda, preservar a sua flexibilidade para formar profissionais com as competências e habilidades descritas no seu artigo $4^{\circ}$ (BRASIL, 2005).

Nessa mesma edição da RBA, o diretor da Câmara de Formação Profissional do CFA afirma que a profissão do administrador demanda muitas habilidades, trazendo à tona a importância das metodologias de ensino utilizadas nos cursos de administração busquem retratar um ensino e aprendizagem fundamentados teoricamente e que haja conexão com o mundo real, com problemas práticos aplicados aos conteúdos e que disponha de projetos de investigação multidisciplinar. Ele defende que o professor torne-se um orientador ou mediador, e não apenas um mero transmissor de conhecimentos, tendo como desdobramento a mudança do papel do aluno, deixando de ser um "coadjuvante" e passando a ser um "protagonista". Em outras palavras, ele sugere que o modelo de educação superior faça uma transposição: do ensino à aprendizagem. Para tanto, o professor deve lançar mão de estudos de caso, trabalhos em grupo, discussão de soluções para problemas simulados, atividades essas que buscam aproximar os estudantes da pratica nas empresas e, assim desenvolver as competências requeridas pelo mercado de trabalho. Isso vai ao encontro à posição de Antunes (2002) de que na sala de aula, a diferença em educar para competências se explicita na forma como as informações são trabalhadas, atribuindo-lhes um significado contextualizado e ligado à vida profissional do estudante, buscando construir o conhecimento com ele.

Para Burnier (200I), a tarefa da educação deve ser sempre a de formar o ser humano em todas as suas capacidades, baseado em um trabalho com os saberes que circulam na sociedade. Para garantir que os conhecimentos ou conteúdos trabalhados tenham um significado para o estudante, os conhecimentos não devem ser divididos em disciplinas. Separá-los em disciplinas é uma operação que tem facilitado à aquisição de conhecimentos, mas que tem, por outro lado, destituído muitas vezes esses conhecimentos do seu significado. Na vida, os conteúdos são todos integrados.

Um ambiente de negócios e progresso tecnológico em constante mutação, e que acabam causando alterações nas forças de trabalho e nas 
suas qualificações bem como nas organizações produtivas, formam os maiores direcionadores de mudança dos cursos de Administração. Assim sendo, este artigo se propõe a relatar a experiência na estruturação de um Projeto Pedagógico de Curso (PPC) em uma IES situada na Região Metropolitana de São Paulo (RMSP), trazendo à discussão alguns desdobramentos didático-pedagógicos necessários e mudanças acerca da construção de competências para os cursos de administração. Os autores deste artigo iniciaram este PPC em outubro de 2012 e implantaram recentemente na IES acima. O PPC por competências não é novidade, como pode ser observado nas experiências de Oliveira e Chamberlain (20II), entretanto, estes autores realizaram estudos em cursos de engenharia. Este trabalho se propõe a relatar experiências em um curso de Administração.

Este trabalho apresentará na seção a seguir uma breve contextualização teórica na busca de buscar uma melhor compreensão acerca do objeto de estudo; na sequência, a metodologia de pesquisa adotada; em seguida, serão expostas as experiências vivenciadas pelos autores deste trabalho na concepção e implantação do PPC; e por fim as considerações finais e recomendações apresentadas pelos autores para futuros estudos referentes ao processo de elaboração de um PPC. 
REFERENCIAL TEÓRICO

\section{COMPETÊNCIA: SER, SABER E FAZER}

Definir competência não é uma tarefa simples. Sua utilização em diversas áreas do saber faz com que seja concebida sob diferentes óticas ou perspectivas. A palavra competência deriva do Latim, "competere", originada da composição da composição do prefixo "com”, cujo significado é conjunto e com o verbo "petere", cujo significado é pedir com instância (RABECHINI JR.; CARVALHO, 2003). As definições de competência, segundo Spencer e Spencer (1993), apontam para cinco características básicas: (a) motivações que determinam o comportamento das pessoas para determinados tipos de ações; (b) traços de personalidade que justificam os tipos de reações a determinadas situações; (c) capacidades pessoais, valores relacionados com as atitudes e autoimagem; (d) conhecimentos; (e) e finalmente, as habilidades, no sentido de capacidade para realizar determinado tipo de atividades físicas e mentais.

Para Perrenoud (1999), competência é a capacidade de articular um conjunto de esquemas, situando-se, portanto, além dos conhecimentos, permitindo mobilizar os conhecimentos na situação, no momento certo e com discernimento. Fleury (2002) define competência como a junção entre o saber teórico (conhecimento - saber) a habilidade (tarefa - saber fazer) e ao ser atitude (atitude - saber ser). Para Menino (2006), o conceito de competência está ligado a uma performance superior do individuo perante uma situação, sem se confundir com a aptidão, ou apenas, habilidades e conhecimentos, mas uma soma e integração dos dois. É característica fundamental da competência ter um caráter dinâmico, de fluxo e não de estoque de conhecimento, voltado para as atividades-meio em detrimento das atividades-fim e focalizado no individuo. Conforme Parecer I6/oo do CNE, ser competente foi considerado ser capaz de mobilizar conhecimentos, informações e até mesmo hábitos para aplicá-los com capacidade de julgamento, em situações reais e concretas.

$\mathrm{Na}$ visão de Leboyer (I997), competências são repertórios de comportamentos que algumas pessoas dominam melhor do que outras e 
que por consequência as torna eficazes numa situação determinada. Para Ribeiro e Guimarães (1998) são características subjacentes a uma pessoa que estão casualmente relacionadas a um desempenho satisfatório num posto de trabalho. De acordo com Ducci (1997), referem-se à capacidade produtiva de um indivíduo, medida em termos de desempenho real e não meramente pela agregação de conhecimentos, habilidades, destrezas e atitudes necessárias, mas não suficientes para um desempenho produtivo em um contexto de trabalho. A competência é um saber agir responsável e reconhecido, que implica mobilizar, integrar, transferir conhecimentos, recursos e habilidades, que agreguem valor econômico à organização e valor social ao indivíduo (FLEURY; FLEURY, 2000). Para a Organização Internacional do Trabalho (OIT), o conceito de competência refere-se à construção social de aprendizagens significativas e úteis para o desempenho produtivo numa situação real de trabalho, que se obtêm não apenas mediante a instrução, mas também em grande medida mediante a aprendizagem por experiência em situações concretas de trabalho (DUCCI, 1997).

Portanto, todas as definições são muito semelhantes entre si. Para efeitos desse artigo, será adotada a definição de Fleury (2002), isto é, o entrecruzamento de três eixos, formado pela pessoa (sua bibliografia, o saber ser), pela sua formação educacional (o saber) e pela sua experiência profissional (o saber fazer). Entretanto, os três eixos de competências apresentados pela autora somente terão o efeito desejado no indivíduo se produzir resultados tanto a ele quanto à organização que "contratar" ou requerer suas competências.

\section{PEDAGOGIA DAS COMPETÊNCIAS E A FORMAÇÃO POR COMPETÊNCIA}

Esses dois modelos pedagógicos são parte do movimento denominado "Ensino baseado em competências" surgido na década de 1970 e possuem os mesmos fundamentos (SIQUEIRA; NUNES, 2OII).

seis princípios básicos de uma pedagogia das competências merecem maior atenção, como segue no Quadro I (BURNIER, 200I). 
Quadro I Princípios Pedagógicos de Competências

\begin{tabular}{|c|c|}
\hline $\begin{array}{l}\text { Principios Pedagógicos de } \\
\text { Competências }\end{array}$ & Conceitos \\
\hline $\begin{array}{l}\text { Formação humana integral, } \\
\text { sólida e omnilateral só são } \\
\text { possíveis com justiça social }\end{array}$ & $\begin{array}{l}\text { Tanto a educação geral quanto a profissional, ou quaisquer outros } \\
\text { processos de formação humana estão cada vez mais atentos aos } \\
\text { novos desafios que os indivíduos e os grupos sociais precisam enfren- } \\
\text { tar. }\end{array}$ \\
\hline Significado da aprendizagem & $\begin{array}{l}\text { As novas pedagogias acreditam que o aluno implicado, envolvido e } \\
\text { interessado aprende com uma energia incomparável, e, portanto, é } \\
\text { preciso tornar os saberes significativos interessantes. }\end{array}$ \\
\hline $\begin{array}{l}\text { Papel dos saberes dos alunos } \\
\text { nas atividades educativas }\end{array}$ & $\begin{array}{l}\text { As atividades de ensino-aprendizagem devem permitir a mais ampla } \\
\text { circulação de informações e conhecimentos anteriores dos alunos, de } \\
\text { suas visões de mundo e da vida profissional. }\end{array}$ \\
\hline $\begin{array}{l}\text { Diversificação das } \\
\text { atividades formativas }\end{array}$ & $\begin{array}{l}\text { Desenvolver competências exige que se programem atividades de } \\
\text { acordo com o tipo de experiência que cada uma delas proporciona } \\
\text { ao aluno: algumas desenvolvem relacionamento interpessoal, de } \\
\text { crítica, de síntese, de solução de problemas, etc. }\end{array}$ \\
\hline Trabalho coletivo & $\begin{array}{l}\text { É um dos caminhos fundamentais da formação do aluno e por sua } \\
\text { condição de favorecer o desenvolvimento de habilidades sociais e } \\
\text { éticas. }\end{array}$ \\
\hline $\begin{array}{l}\text { Investigação integrada ao } \\
\text { ensino-aprendizagem }\end{array}$ & $\begin{array}{l}\text { Perguntar é colocar-se na posição de investigação, é reconhecer } \\
\text { que o que se sabe é sempre questionável e que em qualquer ponto } \\
\text { que estejamos é possível crescer. O conhecimento não deve gerar } \\
\text { respostas definitivas, e sim perguntas inteligentes. }\end{array}$ \\
\hline
\end{tabular}

Fonte: Adaptado pelos autores com base em Burnier (2001).

A formação por competências ou a pedagogia das competências refere-se a um processo que visa desenvolver no estudante a capacidade de aplicar os conhecimentos adquiridos, em diferentes contextos e situações, e impõe uma mudança do foco tradicional de reprodução do conhecimento e conteúdos a serem ensinados para as competências a serem construídas e desenvolvidas (MENINO, 2006; PERRENOUD, 1999). Os pressupostos da formação por competências são métodos formativos e avaliação (SIQUEIRA; NUNES, 20II). No primeiro pressuposto, os conteúdos deixam de serem os fins para se tornarem os meios e o uso de metodologias de ensino diversificadas é valorizado nesse contexto, retirando o professor do centro do processo e colocando o estudante como sujeito ativo da sua formação. Um documento da Secretaria de Educação Média e Tecnológica SEMTEC (2000), do MEC, está bem alinhado com esse pressuposto e mostra a mudança do paradigma para o ensino no Quadro 2. 
Quadro 2 Mudanças de paradigma

\begin{tabular}{ll} 
Paradigma em superação & Paradigma em implantação \\
\hline Foco nos conteúdos a serem ensinados & $\begin{array}{l}\text { Foco nas competências a serem desenvolvidas e } \\
\text { nos saberes a serem construídos }\end{array}$ \\
$\begin{array}{l}\text { Currículo como fim, como conjunto } \\
\text { regulamentado de disciplinas }\end{array}$ & $\begin{array}{l}\text { Currículo como conjunto integrado e articulado } \\
\text { de situações-meio, pedagogicamente concebidas e } \\
\text { organizadas para promover aprendizagens profissionais } \\
\text { significativas }\end{array}$ \\
\hline Alvo de controle oficial: & $\begin{array}{l}\text { Alvo do controle oficial: } \\
\text { cumprimento do Currículo }\end{array}$ \\
\hline
\end{tabular}

Fonte: Adaptado pelos autores com base em SEMTEC (2000).

Enfim, o documento do MEC explicita que os métodos e os processos empregados deixam de ter um papel secundário para se identificarem com o exercício das competências, por meio de problemas/projetos e situaçõesmeio. Por sua vez, no segundo pressuposto, o processo de avaliação é tido como um mecanismo dos saberes e capacidades desenvolvidas, o que remete ao estudo deste artigo.

\section{O PAPEL DA APRENDIZAGEM SIGNIFICATIVA NA PEDAGOGIA E FORMAÇÃO POR COMPETÊNCIA}

O conceito central da teoria de Ausubel é o de aprendizagem significativa, um processo pelo qual uma nova informação se relaciona, de maneira não literal e não arbitrária, a um aspecto relevante da estrutura cognitiva do individuo. Neste processo, a nova informação interage com uma estrutura de conhecimento especifica, a qual Ausubel chama de "conceito subsunçor" existente na estrutura cognitiva de quem aprende (MOREIRA, 2006). O autor segue afirmando que a aprendizagem significativa caracteriza-se por uma interação (não uma simples associação), entre aspectos específicos e relevantes da estrutura cognitiva e as novas informações, pelas quais estas adquirem significado e são integradas à estrutura cognitiva de maneira não arbitrária e não literal, contribuindo para a elaboração e estabilidade dos subsunçores preexistentes da própria estrutura cognitiva.

Em contraposição com aprendizagem significativa, Ausubel define aprendizagem mecânica como sendo aquela em que novas informações 
são aprendidas praticamente sem interagirem com conceitos relevantes existentes na estrutura cognitiva. A nova informação é armazenada de maneira arbitrária e literal, não interagindo com aquela já existente na estrutura cognitiva e pouco ou nada contribuindo para sua elaboração e diferenciação (Moreira, 2006). Tendo em vista a contribuição para a aprendizagem significativa na pedagogia e formação por competência, é possível identificar: a inter-relação contínua de conceitos; a retenção de conhecimento; e a atribuição de significados idiossincráticos.

Por fim, na perspectiva de aprendizagem significativa, o ensino construtivista implica em deixar de ver o estudante como um receptor de conhecimentos e passar a considerá-lo como agente de uma construção, que é a sua própria estrutura cognitiva. O professor deve propor estratégia de aprendizagem e tarefas escolares que exijam do estudante apresentar o significado claro do conceito e transformação do conhecimento adquirido. O docente deve ser o mediador dessa construção (ALMEIDA, 2007). 


\section{METODOLOGIA DE PESQUISA}

Este estudo é qualitativo, pois a análise e discussão dos resultados busca explicar, com base nos documentos e entrevistas, todo o processo vivido pelos autores na elaboração e implantação do PPC na IES, tendo em vista a contribuição para futuros estudiosos do tema e, ainda para aqueles que buscam alternativas de aprimoramento dos PPCS de IES.

No que se refere à definição do tipo de pesquisa, pode-se enquadrá-la, com relação aos fins, como sendo descritiva, porque busca descrever e relatar a experiência na elaboração de um PPC em uma IES situada na RMSP orientado à formação de competências de alunos em um curso de Administração. A estratégia de abordagem é o estudo de caso dessa IEs. Por sua vez, com relação aos meios, pode-se caracterizá-la como sendo uma pesquisa ação, uma vez que é concebida e realizada por meio de uma estreita associação com uma ação ou resolução de um problema coletivo. Os autores deste artigo participaram ativamente de todas as etapas e sua participação e intervenção foram fundamentais para a elaboração deste estudo.

Como técnica de coleta de dados, foi realizada uma pesquisa documental baseada em uma série de documentos internos e externos a IES - o próprio PPC da IES, o Plano Desenvolvimento Institucional(PDI), a Resolução 04/2005 do CNE, a Pesquisa Nacional CFA/CRA de 20II, materiais de uma consultoria especializada em desenvolvimento de talentos e seleção de trainees. Especificamente para o desenvolvimento das habilidades e competências, os autores se basearam nas DCN da Resolução 04/2005, da Pesquisa Nacional CFA/CRA de 20 Ir e dos materiais de uma consultoria especializada em desenvolvimento de talentos e seleção de trainees.

Não consta desse trabalho uma amostra, isto é, participantes da pesquisa, pois este se propõe a relatar a experiência na estruturação de um Projeto Pedagógico de Curso (PPC) em que os alunos não foram envolvidos.

A concepção, desenvolvimento e implantação de um novo PPC para a IES teve início em outubro de 2012 - com ideias e discussões; passando pelo planejamento em 2013 - com a abertura para contribuição do reitor, do vice-reitor, dos coordenadores e dos professores da instituição; e por fim, a implantação em fevereiro de 20I4 - como uma nova estrutura curricular baseada em competências. 


\section{ANÁLISE E DISCUSSÃO DOS RESULTADOS}

\section{ETAPA 1: OBJETIVO DO PPC DA IES}

O pPC do curso baseou-se no marco legal que são as DCN Diretrizes Curriculares Nacionais do curso de ADM além de refletir a finalidade dessa IEs explicitado no seu PDI. Um dos componentes principais do PPC é o perfil do egresso, que estabelece as habilidades e competências que o egresso deve adquirir ao longo do curso para sua inserção no mercado de trabalho.

A finalidade dessa IES consiste em preservar a tradição de excelência no ensino voltado à sociedade e o desafio de mantê-lo adequado às rápidas mudanças do mundo corporativo, que exige uma demanda de mão de obra cada vez mais capacitada para a inovação contínua e adaptação a novos ambientes e situações. Como resultado, o objetivo do projeto pedagógico é desenvolver as competências profissionais que são requeridas do egresso pelo mercado de trabalho, além de contribuir para o esforço de inovação, criação e transformação do seu ambiente de trabalho, colaborando, por sua vez, para o desenvolvimento das competências essenciais da sua organização. Segundo Menino (2006) o que distingue a performance do estudante não é a quantidade de conhecimentos que ele adquire, mas sim, a forma como o aluno organiza, integra e articula.

\section{ETAPA 2: DEFINIÇÃO DAS COMPETÊNCIAS, SUA SEQUÊNCIA E SEUS CONTEÚDOS}

Tendo a clareza do objetivo do PPC, o passo seguinte foi levantar as competências e as habilidades apresentadas na Resolução 04/2005 e, logo em seguida, ordená-las logicamente para que faça sentido aos alunos que ingressarem no curso de Administração, como apresentado no Quadro 3. Cabe ressaltar que as competências dessa Resolução foram dispostas em uma sequência adequada para o aprendizado do aluno à medida que ele fosse progredindo ao longo do curso.

O próximo passo foi categorizar as competências "chave", para chegar a essas I2 competências "chave", foram consideradas as competências e habilidades da 
Resolução 04/2005, as competências do administrador descritas na Pesquisa Nacional do CFA/CRAs de 2OII - que foram sumarizadas: (a) identificar problemas; (b) formular problemas e implantar soluções; (c) ser capaz de enfrentar desafios e solucionar conflitos; (d) desenvolver raciocínio lógico, crítico e analítico; (e) e assumir o processo decisório das ações de planejamento, organização, direção e controle - e as demandadas pelo mercado de trabalho disponibilizado pela consultoria especializada em desenvolvimento de talentos. A definição das doze competências chave encontra-se no Anexo I.

Na sequência, após a determinação das competências "chave", foram desenvolvidos os conteúdos necessários para o aprendizado de cada grupo de competências e, como sugere as DCN, enquadrá-las em categorias: formação básica, estudos quantitativos, formação profissional e formação complementar.

Quadro 3 Competências e Habilidades conforme Resolução 04/2005 do MEC

\begin{tabular}{|c|c|c|c|}
\hline $\begin{array}{l}\text { Competências e habilidades } \\
\text { conforme Res. } 04 / 2005 \text { do } \\
\text { MEC }\end{array}$ & $\begin{array}{l}\text { Competências } \\
\text { chave }\end{array}$ & Conteúdo necessário & $\begin{array}{l}\text { Campo de } \\
\text { formação (*) }\end{array}$ \\
\hline $\begin{array}{l}\text { Desenvolver expressão e } \\
\text { comunicação compatíveis } \\
\text { com o exercício profissional, } \\
\text { inclusive nos processos de } \\
\text { negociação e nas comunica- } \\
\text { ções interpessoais. }\end{array}$ & $\begin{array}{l}\text { Comunicação } \\
\text { Negociação }\end{array}$ & $\begin{array}{l}\text { Recursos humanos e comuni- } \\
\text { cação em um ambiente pro- } \\
\text { fissional, técnicas de negocia- } \\
\text { ção e persuasão. }\end{array}$ & Formação básica \\
\hline $\begin{array}{l}\text { Desenvolver raciocínio } \\
\text { logico, crítico e analítico para } \\
\text { operar com valores e formu- } \\
\text { lações matemáticas presen- } \\
\text { tes nas relações formais e } \\
\text { causais entre fenômenos } \\
\text { produtivos, administrativos } \\
\text { e de controle, e expressando- } \\
\text {-se de modo critico e criativo } \\
\text { diante dos diferentes contex- } \\
\text { tos organizacionais e sociais. }\end{array}$ & $\begin{array}{l}\text { Raciocínio } \\
\text { lógico, crítico e } \\
\text { analítico. } \\
\text { Comunicação }\end{array}$ & $\begin{array}{l}\text { Modelos matemáticos e esta- } \\
\text { tísticos, modelos de tomada } \\
\text { de decisão, estudos orga- } \\
\text { nizacionais e de sistemas } \\
\text { sociais e contabilidade. } \\
\text { Estratégia Empresarial. }\end{array}$ & $\begin{array}{l}\text { Estudos } \\
\text { quantitativos } \\
\text { e formação } \\
\text { profissional }\end{array}$ \\
\hline $\begin{array}{l}\text { Ter iniciativa, criatividade, } \\
\text { determinação, vontade poli- } \\
\text { tica e administrativa, von- } \\
\text { tade de aprender, abertura } \\
\text { às mudanças e consciência } \\
\text { da qualidade e das implica- } \\
\text { ções éticas do seu exercício } \\
\text { profissional. }\end{array}$ & $\begin{array}{l}\text { Criatividade e } \\
\text { inovação } \\
\text { Adaptação e } \\
\text { flexibilidade }\end{array}$ & $\begin{array}{l}\text { Governança profissional, } \\
\text { estudos comportamentais, } \\
\text { criatividade e inovação, sus- } \\
\text { tentabilidade e responsabili- } \\
\text { dade social. }\end{array}$ & $\begin{array}{l}\text { Formação básica e } \\
\text { complementar }\end{array}$ \\
\hline
\end{tabular}




\begin{tabular}{|c|c|c|c|}
\hline $\begin{array}{l}\text { Competências e habilidades } \\
\text { conforme Res. 04/2005 do } \\
\text { MEC }\end{array}$ & $\begin{array}{l}\text { Competências } \\
\text { chave }\end{array}$ & Conteúdo necessário & $\begin{array}{l}\text { Campo de } \\
\text { formação (*) }\end{array}$ \\
\hline $\begin{array}{l}\text { Desenvolver capacidade de } \\
\text { transferir conhecimentos } \\
\text { da vida e da experiência } \\
\text { cotidianas para o ambiente } \\
\text { de trabalho e do seu campo } \\
\text { de atuação em diferentes } \\
\text { modelos organizacionais, } \\
\text { revelando-se profissional } \\
\text { adaptável. }\end{array}$ & $\begin{array}{l}\text { Gestão do } \\
\text { conhecimento } \\
\text { Adaptação e } \\
\text { flexibilidade } \\
\text { Visão sistêmica }\end{array}$ & $\begin{array}{l}\text { Modelos organizacionais, } \\
\text { trabalho em equipe e estu- } \\
\text { dos comportamentais, ges- } \\
\text { tão do conhecimento, gestão } \\
\text { tecnológica, gestão politica } \\
\text { e econômica (macro e micro), } \\
\text { inteligência competitiva }\end{array}$ & $\begin{array}{l}\text { Formação básica, } \\
\text { profissional e } \\
\text { complementar }\end{array}$ \\
\hline $\begin{array}{l}\text { Reconhecer e definir proble- } \\
\text { mas, equacionar soluções, } \\
\text { pensar estrategicamente, } \\
\text { introduzir modificações no } \\
\text { processo produtivo, atuar } \\
\text { preventivamente, transferir } \\
\text { e generalizar conhecimen- } \\
\text { tos e exercer o processo de } \\
\text { tomada de decisão }\end{array}$ & $\begin{array}{l}\text { Visão de } \\
\text { negócio e de } \\
\text { mercado } \\
\text { Tomada de } \\
\text { decisão e } \\
\text { liderança }\end{array}$ & $\begin{array}{l}\text { Estratégia competitiva, } \\
\text { modelos de tomada de deci- } \\
\text { são, métodos quantitativos, } \\
\text { gestão de processos, ciên- } \\
\text { cias jurídicas, modelos de } \\
\text { negócio e finanças. Gestão } \\
\text { de Projetos }\end{array}$ & $\begin{array}{l}\text { Formação básica } \\
\text { e profissional } \\
\text { e estudos } \\
\text { quantitativos }\end{array}$ \\
\hline $\begin{array}{l}\text { Refletir e atuar criticamente } \\
\text { sobre a esfera da produção, } \\
\text { compreendendo sua posi- } \\
\text { ção e função na estrutura } \\
\text { produtiva sob seu controle } \\
\text { e gerenciamento }\end{array}$ & Visão sistêmica & $\begin{array}{l}\text { Gestão logística e de supply } \\
\text { chain, estudos sobre quali- } \\
\text { dade, gestão de serviços e } \\
\text { gestão de processos. }\end{array}$ & $\begin{array}{l}\text { Formação } \\
\text { profissional }\end{array}$ \\
\hline $\begin{array}{l}\text { Desenvolver capacidade } \\
\text { para elaborar, implantar e } \\
\text { consolidar projetos em orga- } \\
\text { nizações }\end{array}$ & $\begin{array}{l}\text { Orientação a } \\
\text { resultado } \\
\text { Relacionamento } \\
\text { interpessoal }\end{array}$ & $\begin{array}{l}\text { Gestão de projetos, inova- } \\
\text { ção, custos, analise de riscos, } \\
\text { gestão de pessoas, estratégia, } \\
\text { empreendedorismo e traba- } \\
\text { lho do curso. }\end{array}$ & $\begin{array}{l}\text { Formação } \\
\text { profissional e } \\
\text { complementar }\end{array}$ \\
\hline $\begin{array}{l}\text { Desenvolver capacidade } \\
\text { para realizar consultorias } \\
\text { em gestão e administração, } \\
\text { pareceres e pericias admi- } \\
\text { nistrativas, gerenciais, orga- } \\
\text { nizacionais, estratégicos e } \\
\text { operacionais }\end{array}$ & $\begin{array}{l}\text { Relacionamento } \\
\text { interpessoal } \\
\text { Orientação ao } \\
\text { cliente }\end{array}$ & $\begin{array}{l}\text { Trabalho em equipe e áreas } \\
\text { de formação profissional, } \\
\text { como recursos humanos, } \\
\text { finanças, marketing, sistema } \\
\text { de informação, operações, } \\
\text { estratégia e ferramentas de } \\
\text { análise, terceirização, técni- } \\
\text { cas de projetos e pesquisa. }\end{array}$ & $\begin{array}{l}\text { Formação } \\
\text { profissional }\end{array}$ \\
\hline
\end{tabular}

$\left.{ }^{*}\right)$ conforme descritos nas DCN 


\section{ETAPA 3: DEFINIÇÃO DOS COMPONENTES CURRICULARES E OBJETIVOS}

O próximo desafio foi a identificação de componentes curriculares. Com base nos conteúdos necessários em cada competência chave, estes foram transformados em componentes curriculares e devidamente alinhados com as competências a serem desenvolvidas em cada ciclo. Isso nos possibilita saber que competências são desenvolvidas em cada semestre de modo cumulativo e contínuo no transcorrer do curso.

É possível observarno Quadro 4, um exemplo da organização dos componentes curriculares do $\mathrm{I}^{\mathrm{o}}$ semestre, onde as colunas de i a 8 estão relacionadas as competências "chave", ordenadas pelos pesquisadores, e as "bolinhas cheias" representam as competências primárias e as "vazias" as secundárias.

Quadro 4 Itinerário das Competências nos Componentes Curriculares

\begin{tabular}{|c|c|c|c|c|c|c|c|c|}
\hline $1^{\circ} \mathrm{Ciclo}$ & 1 & 2 & 3 & 4 & 5 & 6 & 7 & 8 \\
\hline Fundamentos da Administração & $\circ$ & $\bullet$ & & & & & & \\
\hline Linguagem e Gêneros Textuais & $\bullet$ & & & & & & & \\
\hline Ética nas Organizações & ० & & $\bullet$ & & & & & \\
\hline Sociologia Aplicada à Organização & $\circ$ & & & $\bullet$ & & & & \\
\hline Matemática Aplicada à Organização & & $\bullet$ & & & & & & \\
\hline Estudos em Macroeconomia & $\circ$ & & $\bullet$ & & & & & \\
\hline Ensino Social e Cristão & ० & & $\bullet$ & & & & & \\
\hline
\end{tabular}

Legenda 1: 1: Comunicação e Negociação; 2: Raciocínio Lógico, Crítico e Analítico e Comunicação; 3: Criatividade, Inovação, Adaptação e Flexibilidade; 4: Gestão do Conhecimento, Adaptação, Flexibilidade e Visão Sistêmica;5:VisãodeNegóciosedeMercado,TomadadeDecisão,LiderançaeVisãoSistêmica;6:VisãoSistêmica; 7: Orientação à Resultado e Relacionamento Interpessoal; Orientação à Cliente e Relacionamento Interpessoal. Legenda 2: • Competência(s) Primária(s); ○ Competência(s) Secundária(s).

Contudo, o elemento aglutinador dos componentes curriculares em cada ciclo foi a elaboração de um objetivo para cada ciclo. Na ocasião da distribuição dos componentes curriculares os pesquisadores se perguntaram: "Que critérios devemos utilizar para agrupá-los em um ciclo?"; o critério norteador foi a eleição de um objetivo para cada ciclo que será o foco daquele semestre e onde os componentes curriculares são postos para atendê-lo. Considerando que o itinerário formativo das competências é algo 
presente no curso, os objetivos também deveriam ser progressivos e refletir a evolução do aluno ao longo do curso. Adicionalmente, os pesquisadores discutiram a ideia de destacar um componente em cada ciclo como sendo o integrador, isto é, o que deve integrar os demais componentes curriculares com o intuito de atingir ao objetivo do ciclo. Foi atribuído o nome de componente integrador, que cumpre o papel de aglutinar os conhecimentos apresentados e discutidos nos demais componentes do respectivo ciclo, de modo que todos os conhecimentos façam sentido ao aluno, como apresentado no Quadro 5. Isso desmitifica nos alunos a perspectiva de que os componentes são disciplinas no formato de "conhecimentos" isolados. Para garantir que isso aconteça de forma efetiva, idealizou-se o uso de mapas conceituais como um dos instrumentos de aprendizagem.

Quadro 5 Objetivos e Componentes Integradores da Estrutura Curricular

\begin{tabular}{|c|c|c|}
\hline Ciclos & Objetivos & Componentes Integradores \\
\hline 10 & Introduzir as organizações e o seu papel na sociedade. & Fundamentos da Administração \\
\hline $2^{\circ}$ & Conhecer o ambiente das organizações. & Modelos Organizacionais \\
\hline $3^{\circ}$ & $\begin{array}{l}\text { Analisar e compreender os problemas } \\
\text { organizacionais. }\end{array}$ & Dinâmica de Negócios \\
\hline $4^{\circ}$ & $\begin{array}{l}\text { Compreender a relação das organizações com seus } \\
\text { clientes. }\end{array}$ & Mercados e Consumo \\
\hline $5^{\circ}$ & $\begin{array}{l}\text { Compreender os processos e sistemas para } \\
\text { concepção de negócios. }\end{array}$ & Concepção de Negócios \\
\hline $6^{\circ}$ & $\begin{array}{l}\text { Compreender os processos para a implantação de } \\
\text { negócios. }\end{array}$ & Implantação de Negócios \\
\hline $7^{\circ}$ & Elaborar e gerir projetos organizacionais. & $\begin{array}{l}\text { Administração de Projetos } \\
\text { Organizacionais }\end{array}$ \\
\hline $8^{\circ}$ & Compreender os negócios em rede das organizações. & $\begin{array}{l}\text { Redes de Negócios nas } \\
\text { Organizações. }\end{array}$ \\
\hline
\end{tabular}

Com o intuito de proporcionar uma visão geral desta etapa, o Quadro 6 foi elaborado, com base nos Quadros 4 e 5. É possível observar que as competências, tanto primárias quanto secundárias, concentram-se, em sua maioria, entre as colunas i a 4 nos quatro primeiros ciclos do curso. 
Quadro 6 Grade Curricular do Curso de Administração

\begin{tabular}{|c|c|c|c|c|c|c|c|c|}
\hline Ciclos & & & & & & & & \\
\hline $1^{\circ} \mathrm{Ciclo}$ & 1 & 2 & 3 & 4 & 5 & 6 & 7 & 8 \\
\hline Objetivo: Introduzir as organizações e o seu papel na sociedade & & & & & & & & \\
\hline Fundamentos da Administração (Integradora): 4 horas/aula & $\circ$ & $\bullet$ & & & & & & \\
\hline Linguagem e Gêneros Textuais: 2 horas/aula & $\bullet$ & & & & & & & \\
\hline Ética nas Organizações: 2 horas/aula & $\circ$ & & $\bullet$ & & & & & \\
\hline Sociologia Aplicada à Organização: 2 horas/aula & $\circ$ & & & $\bullet$ & & & & \\
\hline Matemática Aplicada à Organização: 4 horas/aula & & $\bullet$ & & & & & & \\
\hline Estudos em Macroeconomia: 4 horas/aula & $\circ$ & & $\bullet$ & & & & & \\
\hline Ensino Social e Cristão: 2 horas/aula & $\circ$ & & $\bullet$ & & & & & \\
\hline $2^{\circ} \mathrm{Ciclo}$ & 1 & 2 & 3 & 4 & 5 & 6 & 7 & 8 \\
\hline Objetivo: Conhecer o ambiente das organizações & & & & & & & & \\
\hline Modelos Organizacionais (Integradora): 4 horas/aula & $\circ$ & $\bullet$ & & $\bullet$ & & & & \\
\hline Estudos em Microeconomia:4 horas/aula & & $\circ$ & & $\bullet$ & & & & \\
\hline Linguagem e Comunicação Organizacional: 2 horas/aula & $\bullet$ & & & & & & & \\
\hline Contabilidade Financeira: 4 horas/aula & & $\bullet$ & & & & & & \\
\hline Filosofia na Administração: 2 horas/aula & $\circ$ & $\bullet$ & & & & & & \\
\hline Cálculo Básico: 4 horas/aula & & $\bullet$ & & & & & & \\
\hline $3^{\circ} \mathrm{Ciclo}$ & 1 & 2 & 3 & 4 & 5 & 6 & 7 & 8 \\
\hline Objetivo: Analisar e compreender os problemas organizacionais & & & & & & & & \\
\hline Dinâmica de Negócios (Integradora): 4 horas/aula & $\circ$ & $\bullet$ & & $\circ$ & $\bullet$ & & & \\
\hline Matemática Financeira: 4 horas/aula & & $\bullet$ & & & & & & \\
\hline Comportamento Humano nas Organizações: 4 horas/aula & $\circ$ & & $\bullet$ & $\bullet$ & & & & \\
\hline Contabilidade Gerencial: 2 horas/aula & & $\bullet$ & & & $\circ$ & & & \\
\hline Estatística Básica: 4 horas/aula & & $\bullet$ & & & & & & \\
\hline Sistema de Informação Gerencial (SIG): 2 horas/aula & $\circ$ & & & $\bullet$ & & & & \\
\hline $4^{\circ} \mathrm{Ciclo}$ & 1 & 2 & 3 & 4 & 5 & 6 & 7 & 8 \\
\hline Objetivo: Compreender a relação das organizações com seus clie & & & & & & & & \\
\hline Mercados e Consumo (Integradora): 4 horas/aula & $\circ$ & & & $\bullet$ & $\bullet$ & & & \\
\hline Gestão Estratégica de Pessoas: 4 horas/aula & $\circ$ & & $\bullet$ & • & & & & \\
\hline Inteligência Competitiva: 2 horas/aula & $\circ$ & & & $\bullet$ & $\bullet$ & & & \\
\hline Controladoria Empresarial: 4 horas/aula & & & & $\bullet$ & $\bullet$ & & $\circ$ & $\circ$ \\
\hline Estatística Aplicada à Organização: 4 horas/aula & & $\bullet$ & & & & & & \\
\hline Direito do Consumidor e Empresarial: 4 horas/aula & $\circ$ & & & ० & $\bullet$ & & & \\
\hline
\end{tabular}


Legenda 1: 1: Comunicação e Negociação; 2: Raciocínio Lógico, Crítico e Analítico e Comunicação; 3 : Criatividade, Inovação, Adaptação e Flexibilidade; 4: Gestão do Conhecimento, Adaptação, Flexibilidade e Visão Sistêmica; 5: Visão de Negócios e de Mercado, Tomada de Decisão, Liderança e Visão Sistêmica; 6: Visão Sistêmica; 7: Orientação à Resultado e Relacionamento Interpessoal; Orientação à Cliente e Relacionamento Interpessoal.

Legenda 2: • Competência(s) Primária(s); ○ Competência(s) Secundária(s).

As competências das colunas 5 a 8, por sua vez, concentram-se mais nos quatro últimos ciclos do curso (vide Quadro 7).

Diante disso, os Quadros de componentes curriculares (6 e 7), organizados dessa maneira, visam proporcionar ao aluno possibilidades para que ele desenvolva as competências "chave" necessárias em um processo evolutivo ao longo dos 8 ciclos do curso. Os Quadros 6 e 7 buscam apresentar os objetivos e componentes curriculares em cada ciclo, alinhados às competências e às respectivas cargas horárias de aula. $\mathrm{O}$ componente em negrito é o componente integrador do ciclo. Menino (2006) acredita que o caráter dinâmico da formação por competências deve desenvolver o potencial do aluno para trabalhar em ambientes flexíveis e voláteis e prepará-lo para a agregação constante de novos conhecimentos e/ou produção destes e para a mobilidade em múltiplas funções ao longo da vida profissional.

Esta grade curricular do curso de administração compreende, ainda, nos dois últimos ciclos a opção de cursar, em cada um dos ciclos, um componente curricular eletivo.

Quadro 7 Grade Curricular do Curso de Administração

\begin{tabular}{|c|c|c|c|c|c|c|c|c|}
\hline $5^{\circ} \mathrm{Ciclo}$ & 1 & 2 & 3 & 4 & 5 & 6 & 7 & 8 \\
\hline \multicolumn{9}{|l|}{ Objetivo: Compreender os processos para a concepção de negócios } \\
\hline Concepção de Negócios (Integradora): 2 horas/aula & $\circ$ & & & & $\bullet$ & & $\bullet$ & \\
\hline Estratégias de Marketing: Produto, Serviços e Preço: 4 horas/aula & ○ & & ○ & & $\bullet$ & & $\bullet$ & $\circ$ \\
\hline Administração de Logística e Cadeia de Suprimentos: 4 horas/aula & & & & & & $\bullet$ & & \\
\hline Dinâmica de Processos e Sistemas: 4 horas/aula & & & & $\circ$ & $\bullet$ & $\bullet$ & ० & \\
\hline Gestão de Conhecimento e Competências: 4 horas/aula & & & & $\bullet$ & ० & $\bullet$ & ○ & $\bullet$ \\
\hline Direito Tributário: 2 horas/aula & & ○ & & ○ & • & & & \\
\hline Administração Financeira de Curto Prazo: 2 horas/aula & & ○ & & & $\bullet$ & o & ○ & \\
\hline
\end{tabular}


$6^{\circ}$ Ciclo

$\begin{array}{llllllll}1 & 2 & 3 & 4 & 5 & 6 & 7 & 8\end{array}$

Objetivo: Compreender os processos para a implantação de negócios

Implantação de Negócio (Integradora): 2 horas/aula

Estratégia de Marketing: Distribuição e Promoção: 4 horas/aula

Modelos de Tomada de Decisão: 4 horas/aula

Finanças Corporativas: 2 horas/aula

Estratégias Corporativas e de Negócios: 4 horas/aula

Gestão e Liderança de Pessoas: 2 horas/aula

Métodos de Pesquisa e Previsão

$7^{\circ}$ Ciclo

Objetivo: Elaborar e gerir projetos organizacionais

Gestão de Projetos Organizacionais (Integradora): 4 horas/aula

Gestão Estratégica da Inovação: 4 horas/aula

Administração de Operação e Qualidade: 4 horas/aula

Sustentabilidade nas Organizações: 2 horas/aula

$\circ \quad \bullet \quad \bullet$

Eletiva 1: 2 horas/aula $(*)$

Modelos de Avaliação Empresarial: 2 horas/aula

Trabalho de Conclusão TC: 2 horas/aula

$3^{\circ} \mathrm{Ciclo}$

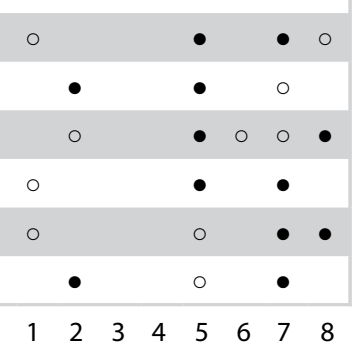

Objetivo: Analisar e compreender os problemas organizacionais

Dinâmica de Negócios (Integradora): 4 horas/aula

Matemática Financeira: 4 horas/aula

Comportamento Humano nas Organizações: 4 horas/aula

Contabilidade Gerencial: 2 horas/aula

Estatística Básica: 4 horas/aula

Sistema de Informação Gerencial (SIG): 2 horas/aula

$4^{\circ} \mathrm{Ciclo}$

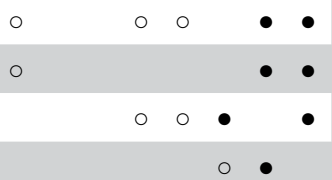

$\circ \bullet$

Objetivo: Compreender os negócios em rede das organizações

Redes de Negócios nas Organizações (Integradora): 4 horas/aula

Eletiva 1: 2 horas/aula $\left({ }^{*}\right)$

Sustentabilidade na Cadeia Produtiva: 2 horas/aula

Gestão de Mudança Organizacional: 4 horas/aula

Administração Estratégica de Serviços em Rede: 2 horas/aula

Projetos de Sistema de Produção: 4 horas/aula

Gestão de Riscos Corporativos: 2 horas/aula

$\begin{array}{lllllllll} & & & & 0 & & \bullet & \bullet \\ 1 & 2 & 3 & 4 & 5 & 6 & 7 & 8\end{array}$

$\begin{array}{llllllll}1 & 2 & 3 & 4 & 5 & 6 & 7 & 8\end{array}$ 
Legenda 1: 1: Comunicação e Negociação; 2: Raciocínio Lógico, Crítico e Analítico e Comunicação; 3 : Criatividade, Inovação, Adaptação e Flexibilidade; 4: Gestão do Conhecimento, Adaptação, Flexibilidade e Visão Sistêmica; 5: Visão de Negócios e de Mercado, Tomada de Decisão, Liderança e Visão Sistêmica; 6: Visão Sistêmica; 7: Orientação à Resultado e Relacionamento Interpessoal; Orientação à Cliente e Relacionamento Interpessoal.

Legenda 2: • Competência(s) Primária(s); ○ Competência(s) Secundária(s).

\section{ETAPA 4: DETERMINAÇÃO DAS METODOLOGIAS DE APRENDIZAGEM}

As diretrizes definidas no PPC tem como desafio quebrar o paradigma do professor como transmissor e reprodutor de conhecimento. Mudar do modelo de ensino para o de aprendizagem. Sob essa nova perspectiva, o docente deve passar a se utilizar de "novas" metodologias de aprendizagem. Duas questões parecem ser irrefutáveis para a implantação das metodologias de aprendizagem: (a) elas devem exigir do aluno um papel mais ativo nas aulas; (b) e elas devem ser mais interativas. Zabala e Arnau (2010) advogam o uso de estratégias metodológicas diversificadas e de aprendizagem significativa que colocam o aluno como sujeito ativo de sua formação. Se os fins são o modelo de aprendizagem, os meios serão as estratégias metodológicas que serão utilizadas para este fim.

Os processos e os métodos ativos de aprendizagem devem ser valorizados como elementos essenciais na construção da formação por competências. Eles retiram o professor do centro do processo, colocando o aluno como sujeito ativo de sua própria formação. O professor deve estar atento para a necessidade de envolver o aluno com as diferentes atividades educativas propostas para a sua formação, de maneira que todos os alunos percebam com clareza o porquê de se estar realizando cada atividade. De acordo com Oliveira e Chamberlain (20II), é fundamental para o desenvolvimento do aluno o delineamento das estratégias metodológicas a serem adotadas pelos professores em sala, uma vez que tais escolhas poderão ser um referencial para a aprendizagem dos alunos.

Para Perrenoud (2000), as estratégias metodológicas dos professores podem desenvolver-se em um duplo registro: criar, intensificar e diversificar o desejo de aprender; favorecer ou reforçar a decisão de aprender. Do desejo 
de saber à decisão de aprender, o caminho é tortuoso. Mesmo diante de alunos que não manifestam nenhuma vontade de saber, uma vontade de aprender já é um consolo. Os métodos ativos estão a serviço do docente na sua missão de ensinar, de reforçar a decisão de aprender nos alunos. $\mathrm{O}$ Quadro 8 apresenta algumas metodologias de aprendizagem que poderão ser adotadas no curso de Administração:

\section{Quadro 8 Estratégias Metodológicas de Aprendizagem}

\begin{tabular}{|c|c|}
\hline $\begin{array}{l}\text { Estratégias } \\
\text { Metodológicas }\end{array}$ & Descritivo \\
\hline $\begin{array}{l}\text { Aproximação entre } \\
\text { Teoria e Prática }\end{array}$ & $\begin{array}{l}\text { Compreende simulações e/ou estudos de casos reais; citando exemplos; } \\
\text { fazendo exercícios práticos; debatendo filmes ilustrativos de casos reais ou notí- } \\
\text { cias de jornais e revistas e correlacionando a teoria com o ambiente empresarial } \\
\text { contemporâneo em termos das estratégias, ferramentas de gestão e tecnologia } \\
\text { utilizadas pelas organizações. }\end{array}$ \\
\hline Ações Resolutivas & $\begin{array}{l}\text { Compreende pesquisas, seminários ou ciclos de debates em que os alunos } \\
\text { interagem na construção do conhecimento por meio de debates sobre temas } \\
\text { ou problemas colocados para discussão. }\end{array}$ \\
\hline Mapa Conceitual & $\begin{array}{l}\text { É uma ferramenta gráfica para a organizaçao e representação do conhecimento } \\
\text { em que os conhecimentos são representados de maneira hierárquica, com } \\
\text { os conceitos mais inclusivos e gerais no topo e os mais especificios e menos } \\
\text { gerais dispostos hieraquicamente abaixo. O ideal é que mapas conceituais } \\
\text { sejam elaborados com base em alguma questão particular que procuramos } \\
\text { responder, o que denominamos questão focal (NOVAK; CAÑAS, 2010). O mapa } \\
\text { conceitual tem o objetivo de mostrar, de forma analítica, a estrutura cognitiva } \\
\text { subjacente a um dado conhecimento e aos seus elementos fundamentais e, } \\
\text { com isso, promover a diferenciação conceitual. O mapa será utilizado após os } \\
\text { alunos já terem familiaridade com a matéria e precedido de explicação pelo } \\
\text { professor. Moreira (2006) entende ser essa a melhor maneira dos mapas serem } \\
\text { empregados como instrumento didático. }\end{array}$ \\
\hline $\begin{array}{l}\text { Trabalho } \\
\text { Interdisciplinar } \\
\text { e Integrador }\end{array}$ & $\begin{array}{l}\text { É a visão integrada dos conhecimentos, habilidades e bases tecnológicas, cientí- } \\
\text { ficas e instrumentais que levam o aluno a construir e desenvolver determinadas } \\
\text { competências. Este trabalho será coordenado pelo professor do componente } \\
\text { integrador de cada ciclo. Favorece a construção de uma visão global, funda- } \\
\text { mentada numa perspectiva relacional entre as disciplinas integrando-as e } \\
\text { articulando-as. Menino (2006) e Perrenoud (1999) reconhecem a utilidade de } \\
\text { trabalho interdisciplinar. }\end{array}$ \\
\hline
\end{tabular}

Os docentes são estimulados a fazer uso do mapa conceitual nas disciplinas de cada ciclo. Com base nesses mapas, os estudantes poderão ainda elaborar o mapa conceitual macro do ciclo indicando as relações entre os principais conceitos de todas as disciplinas ministradas naquele ciclo. Em outras 
palavras, seu objetivo é expressar ao estudante a ideia de interligação entre os componentes. O papel do estudante será o de relacionar por meio do mapa conceitual os elementos cruciais de cada componente e aglutiná-los no componente integrador, de modo a criar relação entre os conteúdos da disciplina de forma interdisciplinar simulando um ambiente organizacional. Assim, serão trabalhados nos estudantes a reflexão e a relação mental dos conteúdos; isso possibilitará que compreendam a inter-relação entre os principais fundamentos da administração. A esse respeito, Novak e Cañas (20Io) observam que estão encontrando em varios livros didáticos de Ciências a inclusão de mapas conceituais como uma forma de resumir o conhecimento adquirido pelos estudantes após estudarem uma unidade ou capitulo. Isso favorece a percepção da relação existente entre parte e todo.

Sobre o uso de metodologias diversas, Siqueira e Nunes (20II) verificaram na sua pesquisa que trabalhos interdisciplinares, estudo de caso e aproximação entre teoria e prática estavam sendo utilizados pelos docentes, embora continuasse a haver prevalencia da aula expositiva. Um dos desafios para a utilização dssas metodologias dá-se devido a necessidade de se balancear os 3 saberes da competencia. Kobayashi e Leite (2004) constataram que as competências gerais e especificas da disciplina Noções de Administração em Enfermagem do Tecnico de Enfermagem estão mais relacionadas a saber fazer $(59 \%$ e $54 \%$ respectivamente) em detrimento do aprender a conhecer $(34 \%$ e $45 \%)$ e a saber ser $(7 \%$ e I\%).

\section{ETAPA 5: DETERMINAÇÃO DOS MÉTODOS AVALIATIVOS}

Um dos pontos fundamentais, críticos e controversos de um PPC baseado em competências é a avaliação, onde notadamente, a avaliação continuada pelo seu caráter dinâmico, flexível e contextualizado do ensino por competências (MENINO, 2006). Ele segue dizendo que a avaliação deve estar voltada para as atuais perspectivas da educação, passando da visão de ensino com transmissão de conteúdos para a de aprendizagem com construção e produção de conhecimentos, com o foco no individuo.

O professor terá a liberdade para definir a melhor forma de medir o aproveitamento dos seus alunos, mediante provas, exercícios, trabalhos, 
mapas conceituais, projetos e outras atividades especificamente propostas nos componentes. Na avaliação por mapa conceitual, a ideia é obter informação sobre como o aluno estrutura, hierarquiza, diferencia e integra conceitos de um determinado componente curricular (MOREIRA, 2006).

O docente irá avaliar o desenvolvimento das competências no seu componente pormeio de indicadores a serem definidos de acordo com a atividade proposta para o desenvolvimento de determinada competência. Tendo em vista a compreensão desta avaliação, cabe uma ilustração: no desenvolvimento da competência Comunicação, o professor pode propor aos alunos algumas atividades ao longo do semestre como apresentações individuais e/ou em grupo, entrega de algum relatório, construção de conhecimento em grupo sobre um determinado tema. Alguns indicadores sugeridos para avaliar o desenvolvimento dessa competência podem ser: (a) expressar ideias e opiniões de forma clara e objetiva; (b) saber ouvir o que os outros falam e absorver a mensagem; (c) mostrar-se aberto a diferentes pontos de vista e opiniões; (d) apresentar argumentos sólidos e fundamentados; (e) e incentivar a troca constante de informação.

Considera-se essencial o acompanhamento pelos professores das atividades feitas pelos alunos durante o semestre letivo, de modo que estes tenham referência do que ser feito e com que padrão, para que haja avaliação correspondente. Isso permitirá aos alunos descobrirem acertos e erros, pontos positivos e pontos para melhorar em seu desempenho. Siqueira e Nunes (20II) apresentaram em seu estudo que nove dentre os 15 professores entrevistados (60\%) fizeram atividades avaliativas ao longo do semestre e comentaram a prova ao devolvê-la.

No entanto, alguns pontos podem dificultar as práticas voltadas para o desenvolvimento das competências e sua consequente avaliação. Um é a quantidade de alunos em sala. Isso pode dificultar o acompanhamento pelo professor de cada aluno de forma única e o seu desenvolvimento em sala, além de tomar tempo excessivo para correção e comentário das provas e atividades, em prejuízo da ênfase ao aprendizado. Outro é a utilização de docentes aulistas que pode não favorecer o envolvimento adequado com a docência. Eles não têm tempo remunerado para desenvolver de projetos e trabalhos extra sala com os alunos, elaborar planejamentos coletivos, compartilhar sua aulas com seus colegas e tampouco tempo com os projetos de pesquisa. Esses dois pontos 
também foram identificados no trabalho de Siqueira e Nunes (20II). Burnier (200I) acredita que o trabalho coletivo deve ser um objetivo institucional, com tempo e remuneração previstos para que ocorra.

\section{ETAPA 6: REUNIÕES, ALINHAMENTO E CAPACITAÇÃO DOS DOCENTES}

Não há como implantar uma nova filosofia, como a proposta, sem o apoio e participação do corpo docente que ministrará aulas no curso. Um grupo de mais de 12 professores, constantes do Núcleo Docente Estruturante (NDE) dos dois campi, contribuiu com a nova proposta em um total de sete reuniões ao longo de 20I3. Este processo participativo fez com que alguns pontos das propostas fossem reajustados e readequados.

Em agosto de 20I3, essa instituição realizou no seu auditório uma mesa redonda para discutir o seguinte tema: Como os componentes curriculares do curso de ADM estão alinhados às competências e habilidades exigidas pelo mercado bem como às listadas nas DCN? Como debatedores, foram convidados o presidente da Angrad (Associação Nacional de Cursos de Graduação em Administração), representando a academia, o Vice Presidente Acadêmico do CRA/sp (representando a profissão), o Diretor Editorial da uma grande editora (representando o mercado editorial), a Diretora de Desenvolvimento de uma empresa de seleção de trainees (representando o mercado de trabalho) e um docente, ex-reitor de uma IEs (representando a classe docente). Essa mesa redonda serviu para balizar o PPC em andamento com os inputs advindos desse encontro.

Em outubro de 20I3, o coordenador do curso, expôs para todo o corpo docente o PPC, os conceitos de competência, formação por competência, metodologias de aprendizagem, os métodos avaliativos e as ações futuras. Um treinamento aos docentes acerca do instrumento didático de aprendizagem denominado mapa conceitual foi providenciado. Ocorreram duas sessões de treinamento, a primeira em dezembro de 20I3; e a segunda em janeiro de 20I4. Na sequência, em fevereiro de 2014 foi conduzido um treinamento sobre mapa conceitual aos alunos que ingressaram no $\mathrm{I}^{\mathrm{o}}$ ciclo. 


\section{ETAPA 7: ELABORAÇÃO DO PLANO DE ENSINO}

A introdução de formação por competência no novo PPC estimulou o coordenador do curso a elaborar um novo Plano de Ensino. Enquanto o plano anterior trabalhava com a questão "O que cada estudante deveria saber ao final dessa disciplina?”, o novo plano muda a questão para “O que cada estudante deveria saber fazer?'. Para Meacham (2013), a visão contemporânea enfatiza ação: pensamento ativo, expressão ativa, preparação ativa para a aprendizagem continua. Engajando-se com um texto ou questão, ordenando informações e argumentos e expressando-se tem precedência sobre a aquisição de conhecimento geral. Na seção dos objetivos do componente curricular, os docentes devem mencionar os objetivos para os 3 saberes da competência: aprender a conhecer (conhecer), saber fazer (habilidade) e saber ser (atitude).

Outras alterações introduzidas no novo plano incluem uma seção para o docente indicar que competência(s) será desenvolvida no componente curricular em questão, que metodologias ativas de aprendizagem serão utilizadas e quais conteúdos que são pré-requisitos para acompanhamento do componente curricular. Isto faz com que o processo tenha continuidade, a aprendizagem seja cumulativa e tenha mais chances de êxito. As demais seções do plano são semelhantes ao plano anterior e dispensam comentários. 


\section{CONSIDERAÇÕES FINAIS}

Os resultados apresentados por Siqueira e Nunes (20II) apontam para a existência de elementos confluentes com a pedagogia das competências, porém aparecem de forma não articulada, sem uma visão de conjunto e sem clareza no entendimento desse modelo de ensino. Isso mostra as enormes dificuldades e obstáculos a serem suplantadas na adoção de competência no projeto pedagógico. Essa é seguramente uma situação que a IES, objeto desse estudo, irá enfrentar.

Esse artigo não tem a pretensão de oferecer uma analise abrangente sobre a formação por competência aplicada em um curso de Administração nem tampouco definir um modelo a ser seguido ou adotado por outras IES. Por ser de objetivo descritivo, o artigo relata a experiência no desenvolvimento do projeto pedagógico baseado em competência em um curso de Administração.

Qualquer implantação de uma nova proposta pedagógica como a pedagogia das competências exige uma mudança de mentalidade e paradigma do coordenador do curso, do seu corpo docente, dos seus estudantes bem como uma reorganização das instituições de ensino que estejam comprometidas com a formação em serviço dos seus estudantes. As DCN constituem-se em um marco importante na formação do profissional de administração. Conforme Oliveira (2005) afirma, as DCN constituem em convite ao diálogo na tentativa de suscitar uma oportunidade de mobilização de esforços que permite não se acomodar a situações de perenidade e conformismo.

Os esforços empreendidos no sentido de inovar suas práticas tem impelido esta IES e o corpo docente de Administração à procura de alternativas que contemplem a realização desse novo currículo e seu PPC. É um processo continuo que se constrói à medida que os desafios se apresentam.

O projeto é ousado tanto por demandar mudança de paradigmas quanto pelo fato de existirem pouquíssimas experiências similares no Brasil, notadamente em curso de Administração. No entanto, como esse projeto será implantado um semestre por vez, existe a possibilidade concreta de 
reavaliar o processo junto aos docentes e estudantes, de forma a fazer os ajustes necessários. Este IES busca ser uma referência a outras no futuro, de modo a fomentar uma educação que seja aderente ao que as organizações solicitam em talentos que buscam no mercado.

Como sugestão de trabalho futuro, seria interessante fazer acompanhamentos contínuos junto aos estudantes ao longo do curso, a fim de verificar a absorção e entendimento desse novo modelo de ensino e o desenvolvimento de suas competências. 


\section{REFERÊNCIAS}

ALMEIDA, L. R. M. Avaliação formativa no contexto da construção do mapa conceitual. Sitientibus, Feira de Santana, n. 36, p.175-195, 2007.

ANTUNES, C. Como desenvolver as competências em sala de aula. 4.ed. Rio de Janeiro: Vozes, 2002.

BRASIL. Conselho Nacional de Educação (CNE). Resolução n ${ }^{\circ} 4$ de 13/07/2005. Brasília, 2005. Institui as Diretrizes Curriculares Nacionais do Curso de Graduação em Administração, bacharelado, a serem observadas pelas Instituições de Ensino Superior em sua organização curricular. Brasília, 2005. Disponível em: $<$ http:// www.udesc.br/arquivos/id_submenu/83/resolucao_2005_4_cne_ces.pdf $>$. Acesso em 20/01/2014.

BURNIER, S. Pedagogia das competências: conteúdos e métodos. Boletim Técnico Senac, v. 27, n. 3, 2001.

CONSELHO NACIONAL DE EDUCAÇÃO. Portaria 776/77 de 03/12/1997. Orienta para as diretrizes curriculares dos cursos de graduação. Brasília, 1999. Disponível em: $<$ http://portal.mec.gov.br/setec/arquivos/pdf_legislacao/superior/legisla_ superior_parecer77697.pdf $>$. Acesso em: 13/02/2014.

DUCCI, M. A. El enfoque de competencia laboral en la perspectiva internacional. In: formación basada en competencia laboral. Montevideo: Cinterfor/OIT, 1997

FLEURY, A.; FLEURY, M. T. L. Estratégias empresariais e formação de competências: Um Quebra-Cabeça Caleidoscópio da Indústria Brasileira. São Paulo: Atlas, 2000.

FLEURY, M. T. L. As pessoas na organização. São Paulo: Editora Gente, 2002.

KOBAYASHI, R. M.; LEITE, M. M. J. Formação de competências administrativas do técnico de enfermagem. Rev. Latino-Am Enfermagem, v. 12, n. 2, p.221-227, 2004.

LEBOYER, C. L. Gestión de las competencias. Barcelona: Ediciones 2000, 1997.

MEACHAM, J. The class of 2025, Time Magazines Europe Ltd, v. 182, n. 15, p. 34-39, October 2013.

MENINO, S.E. Considerações sobre o ensino por competências. In: IX SEMEAD, FEA/ USP, São Paulo, 2006.

MOREIRA, M.A. A teoria da aprendizagem significativa e sua implementação em sala de aula. Brasília: Universidade de Brasília, 2006.

NOVAK, J. D.; CAÑAS, A. J. A teoria subjacente aos mapas conceituais e como elaborálos e usá-los. Práxis Educativa, v. 5, n. 1, p. 9-29, 2010.

OLIVEIRA, A. C. C. O curso de administração à luz das diretrizes curriculares nacionais. Sitientibus, n. 32, p. 29-42, 2005.

OLIVEIRA, V. F.; CHAMBERLAIN, Z. Engenharia sem fronteiras. Passo Fundo: Universidade do Passo Fundo, 2011. 
PERRENOUD, P. Construir as competências desde a escola. Porto Alegre: Artmed, 2000.

PERRENOUD, P. Dez novas competências para ensinar. Porto Alegre: Artmed, 1999.

RABECHINI JR., R.; CARVALHO, M. M. Perfil das competências em equipes de projetos, Revista de Administração de Empresas Eletrônica, v. 2, n. 1, p. 1-18, 2003.

RIBEIRO, L. M. M.; GUIMARÃES, T. A. Competências organizacionais e humanas de uma organização financeira estatal: O Ponto de Vista de seus Gerentes. In: EnANPAD, 22., 1998, Foz do Iguaçu. Anais... Foz do Iguaçu: Anpad, 1998.

SEMTEC (Secretaria de Educação Média e Tecnológica). Educação Profissional:

Referenciais Curriculares Nacionais da Educação de Nível Técnico. Ministério da

Educação. Brasília, 2000. Disponível em: <http://portal.mec.gov.br/setec/arquivos/ pdf/introduc.pdf $>$ Acesso em: 25/01/2014.

SIQUEIRA, L.; NUNES, S. C. Um olhar sobre o projeto pedagógico e as práticas docentes baseados na proposta de formação por competências. Administração: Ensino e Pesquisa, v. 12, n. 2, p.415-445, 2011.

SPENCER, L. M.; SPENCER, S. M. Competence at work: models for superior performance. New York: John Wiley \& Sons, 1993.

ZABALA, M. A.; ARNAU, L. Como aprender e ensinar competências. Porto Alegre: Artmed, 2010. 


\section{ANEXO I - DEFINIÇÃO DAS COMPETÊNCIAS CHAVE}

Tomada de decisão e liderança: capacidade de delegar, reconhecer com justiça e flexibilizar de acordo com a situação, sem deixar de acompanhar e desenvolver com discurso igual à prática. Ser agente na condução de ações de seu pessoal.

Negociação: capacidade para argumentar e conseguir o entendimento, demostrando firmeza e transparência nos posicionamentos, sem ser intransigente. Obtém os melhores resultados para as partes envolvidas.

Comunicação: capacidade de expressar ideias e transmitir informações com linguagem clara e objetiva seja de forma oral ou escrita. Envolve ainda a atitude de valorizar o processo de comunicação transparente e integra.

Relacionamento interpessoal: capacidade de reconhecer, valorizar e adaptar-se às diferenças individuais para construir e manter uma boa rede de contatos (stakeholders). Incentiva na sua equipe um ambiente de apoio e participação.

Raciocínio lógico, crítico e analítico: capacidade de raciocinar rapidamente por meio da percepção (analítico), desenvolver conceitos e ligar ideias que não estão necessariamente ligadas (logico) e saber avaliar um fato, conceito ou situação com criticidade, metodologia, perseverança e determinação (crítico).

Criatividade e inovação: capacidade de gerar ideias originais e úteis e solucionar os problemas do dia-a-dia (criatividade) bem como implantar um novo ou significativamente melhorado produto (bem ou serviço), processo de trabalho, ou prática.

Gestão do conhecimento: capacidade de gerar, codificar, disseminar e se apropriar do conhecimento bem como entender o que cada informação significa e que impactos na organização cada informação pode causar de modo que ela possa ser utilizada para atingir a excelência organizacional. Adaptação e flexibilidade: capacidade de se modificar no organismo de uma organização, de uma forma positiva, em resposta as variações do ambiente e avaliar suas ações como oportunidades de aprendizado.

Visão sistêmica: capacidade de enxergar uma organização por meio dos 
seus sistemas e processos de negócio, entendendo as interdependências entre cada um, visando obter melhores resultados.

Visão de negocio e de mercado: importância de olhar para o mercado e o negócio da organização quando da proposição das soluções. Acompanha tendências de mercado e percebe oportunidades de inovação com objetivo de sustentabilidade e rentabilidade do negócio.

Orientação ao cliente: orienta suas ações para estabelecer vinculo profissional, disponibilidade e flexibilidade para entender, atender e satisfazer o cliente. Olhar com a visão do cliente para todo projeto de marketing, de produção ou estratégia da empresa.

Orientação a resultado: proatividade para atingir e superar as expectativas / metas acordadas, por meio da criação de alternativas para solucionar situações problemas, gerando resultados para o grupo/trabalho. 


\section{DADOS DOS AUTORES}

\section{HONG YUH CHING` hongching@fei.edu.br}

Doutor em Engenharia pela Unicamp

Instituição de vinculação: Centro Universitário da FEI

São Bernardo do Campo/SP - Brasil

Áreas de interesse em pesquisa: Finanças, Sustentabilidade e Gestão de Risco

Corporativo.

* Av. Humberto de Alencar Castelo Branco, 3972

Assunção São Bernardo do Campo/SP 09850-901

EDSON COUTINHO DA SILVA coutinho_ed@hotmail.com

Doutor em Ciências Sociais pela PUC-SP

Instituição de vinculação: Centro Universitário da FEI

São Bernardo do Campo/SP - Brasil

Áreas de interesse em pesquisa: Marketing, Gestão de Projetos e Gestão Pública.

\section{PAULO HENRIQUE TRENTIN trentin@fei.edu.br}

Doutor em História da Ciência pela PUC/SP

Instituição de vinculação: Centro Universitário da FEI

São Bernardo do Campo/SP - Brasil

Áreas de interesse em pesquisa: História da Ciência, Educação Matemática e Uso de

Tecnologias. 